\title{
Mutually Risk Roles of Oral Cleanliness and Stroke- associated Pneumonia in Patients with Acute Ischemic Stroke: A Cross-Sectional Study
}

\author{
Xiaohua Yang \\ Zhujiang Hospital of Southern Medical University
}

\section{Huijuan Chen}

Zhujiang Hospital of Southern Medical University

\section{Wanling Yang}

Zhujiang Hospital of Southern Medical University

\section{Bin Deng}

Zhujiang Hospital of Southern Medical University

\section{Jialing Zheng}

Zhujiang Hospital of Southern Medical University

\section{Juan Wei}

Zhujiang Hospital of Southern Medical University

\section{Chunguang Li}

Zhujiang Hospital of Southern Medical University

\section{Yanjun Huang}

Zhujiang Hospital of Southern Medical University

\section{Xiaoya Gao}

Zhujiang Hospital of Southern Medical University

\section{Haiting Xie}

Zhujiang Hospital of Southern Medical University

\section{Minzi Li}

Zhujiang Hospital of Southern Medical University

\section{Aimin Chen}

Zhujiang Hospital of Southern Medical University

\section{Zhilin Huang}

Zhujiang Hospital of Southern Medical University

\section{Qin Yang}

Zhujiang Hospital of Southern Medical University

\section{Juan He}

Hunan Provincial People's Hospital, Hunan Normal University

\section{Juan Zhang}

Hunan Provincial People's Hospital, Hunan Normal University

\section{Tingting $\mathrm{Hu}$}

Hunan Provincial People's Hospital, Hunan Normal University

\section{Xi Tao}

Hunan Provincial People's Hospital, Hunan Normal University

Qing Wang ( $\sim$ denniswq@yahoo.com ) 


\section{Research}

Keywords: nursing, ischemic stroke, oral hygiene, stroke-associated pneumonia, predictor

Posted Date: July 15th, 2020

DOI: https://doi.org/10.21203/rs.3.rs-42112/v1

License: (c) (i) This work is licensed under a Creative Commons Attribution 4.0 International License. Read Full License 


\section{Abstract}

Background: Stroke-associated pneumonia (SAP) is a major complication after stroke, oral microorganisms are important contributors to SAP. Here, we aimed to investigate whether the oral hygiene was associated with SAP and related risk factors of them in patients with acute ischemic stroke.

Methods: We performed a cross-sectional study that recruited 331 patients with acute ischemic stroke from two medical centers. A series of assessments were performed to evaluate the neurological status and habits of oral hygiene. According to whether the oral hygiene was abnormal and SAP occurred, univariate analyses were performed in cohort 1 (normal / abnormal oral hygiene groups) and cohort 2 (SAP / non-SAP groups). Multiple logistic regression analyses were conducted to confirm risk factors of oral cleanliness and SAP in stroke patients.

Results: A total of 12 and 8 independent variables were included in the model 1 and 2 analysis. After adjusting for confounders, multivariable logistic regression analysis showed that oral cleanliness was not only closely related to SAP $(\mathrm{OR}=2.219, P=0.026)$, dental caries $(\mathrm{OR}=1.292, P=0.005)$ and age $(\mathrm{OR}=1.030, P=0.006)$ in model 1 , but also an independent risk factor for predicting SAP $(\mathrm{OR}=1.678, P=0.001)$ in model 2. Barthel index was a protective factor for oral cleanliness $(\mathrm{OR}=0.986, P=0.019)$ and $\mathrm{SAP}(\mathrm{OR}=0.977, P=0.002)$ in ischemic stroke patients.

Conclusions: Mutually primary risk roles of abnormal oral cleanliness and SAP exist in patients with acute ischemic stroke. Dental caries and aging are important risk factors for oral health disorders. Improving the activities of daily living would have protective effects on both oral hygiene and SAP prevention in stroke patients.

\section{Introduction}

Stroke is a serious life-threatening and crippling cerebrovascular disease [1]. Stroke-associated pneumonia (SAP) is a major complication after stroke and tremendously increases morbidity and mortality[2-4]. A consensus that treatment for early SAP ( $<72$ h of stroke onset) should cover community-acquired pneumonia organisms had been reached by PISCES group [5]. Thus, predicting SAP in the early stage of stroke should be highlighted to improve the prognosis of patients.

Various mechanisms underlying the development of SAP have been identified, in addition to stroke-induced immunosuppression, dysphagia, poor respiratory muscle strength, decreased pulmonary function and respiratory center dysfunction after brain injury also play important roles [5-10]. Among them, oral hygiene is often overlooked. Several lines of recent evidence have indicated that oral hygiene is an important contributor to SAP [3, 7]. Patients with stroke often have difficulties maintaining oral health for a variety of reasons, such as cognitive impairment and oral functional disabilities $[6-8,11]$. Therefore, tremendously increased oral pathogens not only induce the incidence of oral infections but also increase the risk of SAP. Previous studies have demonstrated that oral hygiene care can lower the risk of pneumonia in both non-ventilated and ventilated patients [12-16]. Furthermore, another study suggested that systematic oral hygiene care can decrease the risk of hospital-acquired pneumonia (HAP) in patients with acute-subacute stroke [3, 7]. These results indicate that maintaining oral health in patients with stroke may help to reduce the risk of SAP and improve the prognosis [11].

To our knowledge, there are limited data on the relationship of oral hygiene and its related risk factors with SAP in stroke patients. Whether any prognostic or diagnostic risk factors of oral hygiene exist in acute stroke patients has not been previously investigated. To address these gaps in knowledge, we conducted a large retrospective cohort study to identify the potential and most significant risk factors for SAP, with the aim of validating the potential prognostic or diagnostic clinical variables to facilitate the early prediction of patients with SAP. Therefore, our goals were to 1) investigate whether the oral hygiene of patients with ischemic stroke was associated with SAP and disease severity; 2) explore whether poor oral hygiene is an independent risk factor for predicting SAP. Our study provides strategies for the prevention of poor oral hygiene in these patients. 


\section{Methods}

\section{Patients and Study design}

From May 2019 to April 2020, a total of 875 stroke patients were screened and finally 331 patients were enrolled for this study. All included patients were conscious and clinically diagnosed with ischemic stroke by brain computed tomography (CT, 64-row multidetector) or / and magnetic resonance imaging (1.5T). All SAP was diagnosed by physician according to the consensus of PISCES criteria [17] and confirmed by chest CT ( $<2 \mathrm{~h}$ of stroke onset) [18]. The exclusion criteria were as follows: 1) hemorrhagic stroke; 2) severe aphasia; 3) noncooperation with Mini-mental state examination (MMSE) evaluation; 4) tracheotomy or oral tracheal intubation; 5) primary oral diseases, such as tongue or oral cancer; 6) severe liver (alanine aminotransferase $>200 \mathrm{U} / \mathrm{L}$ ) or kidney (plasma creatinine > $186 \mu \mathrm{mol} / \mathrm{L}$ ) dysfunction; 7) toothless; 8) noncooperation with Beck oral assessment scale (BOAS) inspection; and 9) refusal to take part in the research. Basic demographic information, including gender, age, educational background, course of disease, number of stroke events, vascular risk factors [hypertension, diabetes, coronary heart disease, smoking and body mass index (BMI)], SAP (at the time of investigation) and gastrointestinal diseases (at the time of investigation), was collected from all patients. Neurological function assessments included: the National Institutes of Health Stroke Scale (NIHSS), used to assess neurological deficits; the Barthel Index (BI), used to assess the activities of daily living (ADLs); the MMSE, used to assess cognitive function; and the Water Swallowing Test (WST) scale, used to screen swallowing function in patients with ischemic stroke [19].

BOAS was used to assess the oral cleanliness of all patients [20,21], who were setting as cohort 1 (normal BOAS [ $n=135]$ and abnormal BOAS groups [ $n=196])$. Cohort 2 was set up as SAP and non-SAP groups. The BOAS scale consists of 5 items: lips, gums and oral mucosa, teeth, tongue and saliva. Each item is scored on a 4-point scale from 1 to 4 points. A total BOAS score of 5 is recognized as normal, $6-10$ as mild dysfunction, $11-15$ as moderate dysfunction, and $16-20$ as severe dysfunction. Model 1 and 2 were set up to predict the risk of oral hygiene and SAP in patients with ischemic stroke, respectively.

We used a homemade scale to investigate the recent ( $<3$ days) oral hygiene habits, care styles and objective conditions related to the oral cavities of the ischemic stroke patients. The scale contains 11 items: the number of dental caries, oral cleaners, cleaning methods, frequency of cleaning, attention to oral hygiene and the number of cleansing sites (lips, tongue, gums and oral mucosa, and teeth), whether or not active dentures are used, mouthwash, dental floss, toothbrushes, and the stomach tube. The above BOAS and homemade scales were evaluated by two specialist nurses, and others assessments were performed by two physicians on the first day after admission. Systematic training and guidance were conducted prior to the investigation to reduce the bias in understanding the assessment during the clinical data survey.

\section{Statistical analysis}

All data were analyzed using SPSS 17.0 (IBM Corporation, Armonk, NY, USA). The exploratory analysis method (Kolmogorov-Smirnov) was used to test whether the measurement data of each group followed a normal distribution. The $t$ test was used to compare two normally distributed, homoscedastic, independent samples. The Mann-Whitney U method was used to compare two non-normally distributed, independent samples and grade data. The chi-squared test was used to compare percentage-based data between the two groups in cohort 1 and 2, respectively. The Box-Tidwell method was used to test whether there was a linear relationship between a continuous independent variable and the dependent variable after logit conversion. Tolerance and variance inflation factors were used to exclude collinearity between independent variables. Univariable analysis was performed on the data, and variables with $P<0.2$, indicating potential risk factors, were included in the multivariable logistic stepwise regression analysis. Here, variables were retained if the corresponding $P$ values $\leq 0.05$ and rejected if $P>0.1$. The Hosmer-Lemeshow test was used to judge the goodness of fit of the regression model, and finally, the receiver operating characteristic (ROC) curve was determined for the predicted probability value of the model.

\section{Results}




\section{Patient characteristics}

A total of 875 patients who were diagnosed with ischemic stroke were screened, 544 of whom were excluded according to the exclusion criteria, and 331 patients were finally enrolled for further analysis. The mean age (SD) of the enrolled patients was 64.38 (11.65), and $67.07 \%$ were male (Table 1). According to the score from the BOAS, a scale to assess oral hygiene status, patients were divided into the normal BOAS group $(n=135)$ and the abnormal BOAS group $(n=196)$. In the abnormal BOAS group, 193 patients had mild dysfunction, and 3 had moderate dysfunction. In addition, a total of 70 SAP patients were identified and collectively constituted the SAP group, and 70 ischemic stroke patients without SAP matched by age and gender were selected as the non-SAP group for further analysis (Fig. 1). In terms of independent variable selection, mouthwash and dental floss were excluded because none of the investigated patients used them. 
Table 1

Comparison of basic demographic data between normal and abnormal BOAS groups (Cohort 1) in patients with ischemic stroke, and various factors between the SAP and non-SAP groups (Cohort 2)

\begin{tabular}{|c|c|c|c|c|c|c|c|c|}
\hline \multirow[t]{2}{*}{ Variables } & \multicolumn{4}{|l|}{ Cohort 1} & \multicolumn{4}{|l|}{ Cohort 2} \\
\hline & $\begin{array}{l}\text { Normal } \\
\text { BOAS } \\
\text { group(n = } \\
135)\end{array}$ & $\begin{array}{l}\text { Abnormal } \\
\text { BOAS } \\
\text { group(n } \\
=196)\end{array}$ & $x^{2} / Z / t$ & $P$ & $\begin{array}{l}\text { SAP group } \\
(n=70)\end{array}$ & $\begin{array}{l}\text { Non-SAP } \\
\text { group } \\
(n=70)\end{array}$ & $x^{2} / Z / t$ & $P$ \\
\hline Gender (male) & $\begin{array}{l}88 \\
(65.19 \%)\end{array}$ & $\begin{array}{l}134 \\
(68.37 \%)\end{array}$ & $0.367^{\dagger}$ & 0.545 & $53(75.71 \%)$ & $44(62.86 \%)$ & $2.719^{\dagger}$ & 0.099 \\
\hline Hypertension & $\begin{array}{l}97 \\
(71.85 \%)\end{array}$ & $\begin{array}{l}130 \\
(66.33 \%)\end{array}$ & $1.133^{\dagger}$ & 0.287 & $54(77.14 \%)$ & $48(68.57 \%)$ & $1.300^{\dagger}$ & 0.254 \\
\hline $\begin{array}{l}\text { Diabetes } \\
\text { mellitus }\end{array}$ & $\begin{array}{l}34 \\
(25.19 \%)\end{array}$ & $\begin{array}{l}65 \\
(33.16 \%)\end{array}$ & $2.427^{\dagger}$ & 0.119 & $24(34.29 \%)$ & $21(30.00 \%)$ & $0.295^{\dagger}$ & 0.587 \\
\hline $\begin{array}{l}\text { Coronary heart } \\
\text { disease }\end{array}$ & $11(8.15 \%)$ & $\begin{array}{l}19 \\
(9.69 \%)\end{array}$ & $0.232^{\dagger}$ & 0.630 & $14(24.29 \%)$ & $10(14.29 \%)$ & $0.805^{\dagger}$ & 0.370 \\
\hline Smoking & $\begin{array}{l}56 \\
(41.48 \%)\end{array}$ & $\begin{array}{l}80 \\
(40.82 \%)\end{array}$ & $0.015^{\dagger}$ & 0.904 & $32(45.71 \%)$ & $24(34.29 \%)$ & $1.905^{\dagger}$ & 0.168 \\
\hline SAP & $\begin{array}{l}14 \\
(10.37 \%)\end{array}$ & $\begin{array}{l}56 \\
(28.56 \%)\end{array}$ & $15.881^{\dagger}$ & $0.000^{\star \star \star}$ & & & & \\
\hline $\begin{array}{l}\text { Gastrointestinal } \\
\text { diseases }\end{array}$ & $11(8.15 \%)$ & $\begin{array}{l}21 \\
(10.71 \%)\end{array}$ & $0.603^{\dagger}$ & 0.438 & $4(5.71 \%)$ & $2(2.86 \%)$ & $0.709^{\ddagger}$ & 0.400 \\
\hline Stomach tube & $3(2.22 \%)$ & $\begin{array}{l}16 \\
(8.16 \%)\end{array}$ & $5.215^{\dagger}$ & $0.022^{*}$ & $14(20.00 \%)$ & $2(2.86 \%)$ & $10.161^{\dagger}$ & $0.001^{\star *}$ \\
\hline Active dentures & $\begin{array}{l}19 \\
(14.07 \%)\end{array}$ & $\begin{array}{l}24 \\
(12.24 \%)\end{array}$ & $0.237^{\dagger}$ & 0.627 & & & & \\
\hline Oral cleaners & $\begin{array}{l}126 \\
(93.33 \%)\end{array}$ & $\begin{array}{l}172 \\
(87.76 \%)\end{array}$ & $2.771^{\dagger}$ & 0.096 & & & & \\
\hline Toothbrush & $\begin{array}{l}130 \\
(96.30 \%)\end{array}$ & $\begin{array}{l}180 \\
(91.84 \%)\end{array}$ & $2.676^{\dagger}$ & 0.102 & & & & \\
\hline \multicolumn{9}{|l|}{ Education: } \\
\hline Illiteracy & $24(17.78 \%)$ & $\begin{array}{l}23 \\
(11.73 \%)\end{array}$ & $-0.491 \S$ & 0.623 & & & & \\
\hline Primary & $\begin{array}{l}31 \\
(22.96 \%)\end{array}$ & $\begin{array}{l}57 \\
(29.08 \%)\end{array}$ & & & & & & \\
\hline Secondary & $\begin{array}{l}32 \\
(23.70 \%)\end{array}$ & $\begin{array}{l}62 \\
(31.63 \%)\end{array}$ & & & & & & \\
\hline High & $\begin{array}{l}30 \\
(22.22 \%)\end{array}$ & $\begin{array}{l}38 \\
(19.39 \%)\end{array}$ & & & & & & \\
\hline $\begin{array}{l}\text { University or } \\
\text { above }\end{array}$ & $\begin{array}{l}18 \\
(13.33 \%)\end{array}$ & $\begin{array}{l}16 \\
(8.16 \%)\end{array}$ & & & & & & \\
\hline \multicolumn{9}{|l|}{ WST } \\
\hline Normal & $\begin{array}{l}122 \\
(90.37 \%)\end{array}$ & $\begin{array}{l}147 \\
(75.00 \%)\end{array}$ & $-3.586^{\S}$ & $0.000^{\star \star \star}$ & $46(65.71 \%)$ & $65(92.86 \%)$ & $-4.002^{\S}$ & $0.000^{\star \star \star}$ \\
\hline Doubtful & $10(7.41 \%)$ & $\begin{array}{l}30 \\
(15.31 \%)\end{array}$ & & & $9(12.86 \%)$ & $3(4.29 \%)$ & & \\
\hline
\end{tabular}




\begin{tabular}{|c|c|c|c|c|c|c|c|c|}
\hline \multirow[t]{2}{*}{ Variables } & \multicolumn{4}{|l|}{ Cohort 1} & \multicolumn{4}{|l|}{ Cohort 2} \\
\hline & $\begin{array}{l}\text { Normal } \\
\text { BOAS } \\
\text { group }(n= \\
135)\end{array}$ & $\begin{array}{l}\text { Abnormal } \\
\text { BOAS } \\
\text { group(n } \\
=196)\end{array}$ & $x^{2} / Z / t$ & $P$ & $\begin{array}{l}\text { SAP group } \\
(n=70)\end{array}$ & $\begin{array}{l}\text { Non-SAP } \\
\text { group } \\
(n=70)\end{array}$ & $\chi^{2} / Z / t$ & $P$ \\
\hline Abnormal & $3(2.22 \%)$ & $\begin{array}{l}19 \\
(9.69 \%)\end{array}$ & & & $15(21.43 \%)$ & $2(2.86 \%)$ & & \\
\hline \multicolumn{9}{|l|}{$\begin{array}{l}\text { Attention of oral } \\
\text { hygiene }\end{array}$} \\
\hline Unimportant & $9(6.67 \%)$ & $\begin{array}{l}18 \\
(9.18 \%)\end{array}$ & $-0.166 \S$ & 0.868 & & & & \\
\hline General & $\begin{array}{l}109 \\
(80.74 \%)\end{array}$ & $\begin{array}{l}148 \\
(75.51 \%)\end{array}$ & & & & & & \\
\hline Crucial & $\begin{array}{l}17 \\
(12.59 \%)\end{array}$ & $\begin{array}{l}23 \\
(11.73 \%)\end{array}$ & & & & & & \\
\hline $\begin{array}{l}\text { All- } \\
\text { important }\end{array}$ & $0(0.00 \%)$ & $7(3.57 \%)$ & & & & & & \\
\hline $\begin{array}{l}\text { Age, years } \\
\text { (Mean } \pm \text { SD) }\end{array}$ & $\begin{array}{l}61.35 \pm \\
13.90\end{array}$ & $\begin{array}{l}66.46 \pm \\
9.29\end{array}$ & $-3.739 \|$ & $0.000^{\star \star \star}$ & $\begin{array}{l}68.5(32, \\
85)\end{array}$ & $\begin{array}{l}67.5(51, \\
89)\end{array}$ & $-0.263^{\S}$ & 0.793 \\
\hline $\begin{array}{l}\text { Course of } \\
\text { disease, hours }\end{array}$ & $5(1-28)$ & $5(1,25)$ & $-0.885^{\S}$ & 0.376 & $4(1,12)$ & $5(1,14)$ & $-0.379 \S$ & 0.705 \\
\hline Num. of stroke 9 & $1(1-3)$ & $1(1-2)$ & $-1.058 \S$ & 0.290 & $1(1,3)$ & $1(1,2)$ & $-0.286^{\S}$ & 0.775 \\
\hline $\begin{array}{l}\text { Num. of dental } \\
\text { caries }\end{array}$ & $0(0-5)$ & $1(0-8)$ & $-3.615^{\S}$ & $0.000^{* \star *}$ & & & & \\
\hline $\begin{array}{l}\text { BMI (Mean } \pm \\
\text { SD) }\end{array}$ & $\begin{array}{l}23.97 \pm \\
3.68\end{array}$ & $\begin{array}{l}23.64 \pm \\
3.20\end{array}$ & $0.846 \|$ & 0.398 & $\begin{array}{l}23.01 \pm \\
3.37\end{array}$ & $\begin{array}{l}23.79 \pm \\
3.40\end{array}$ & $1.364^{\|}$ & 0.175 \\
\hline NIHSS ${ }^{9}$ & $2(1-15)$ & $3(0-21)$ & $-3.951^{\S}$ & $0.000^{\star \star}$ & $6(1,21)$ & $3(1,15)$ & $-3.890^{\S}$ & $0.000^{\star \star \star}$ \\
\hline $\mathrm{BI}{ }^{9}$ & $\begin{array}{l}100(15- \\
100)\end{array}$ & $\begin{array}{l}90(0- \\
100)\end{array}$ & $-4.189 \S$ & $0.000^{\star \star \star}$ & $\begin{array}{l}62.5(0 \\
100)\end{array}$ & $\begin{array}{l}87.5(20 \\
100)\end{array}$ & $-3.752^{\S}$ & $0.000^{* \star \star}$ \\
\hline MMSE 9 & $26(4-30)$ & $\begin{array}{l}25(2- \\
30)\end{array}$ & $-2.497 \S$ & $0.013^{*}$ & $20(4,29)$ & $23(2,30)$ & $-0.589 \S$ & 0.556 \\
\hline $\begin{array}{l}\text { Frequency of } \\
\text { cleaning }\end{array}$ & $2(1-4)$ & $2(1-3)$ & $-0.471^{\S}$ & 0.638 & & & & \\
\hline $\begin{array}{l}\text { Num. of } \\
\text { cleaning sites }\end{array}$ & $1(1-4)$ & $1(1-4)$ & $-1.316 \S$ & 0.188 & & & & \\
\hline BOAS score 9 & & & & & $7(5,12)$ & $6(5,9)$ & $-3.770^{\S}$ & $0.000^{\star \star \star}$ \\
\hline
\end{tabular}

Comparisons of basic demographic data between normal and abnormal BOAS groups in patients with ischemic stroke

In this study, patients with abnormal oral hygiene were more likely to present with swallowing dysfunction identified by the WST $\left[n=49(25.00 \%),{ }^{* \star *} P=0.000\right]$ and use of an indwelling stomach tubes $\left[n=16(8.16 \%),{ }^{*} P=0.022\right]$ than patients in the normal group $[n=13(9.63 \%)$ and $n=3(2.22 \%)$, respectively]. The age and number of dental caries in the abnormal BOAS group were obviously higher than those in the normal group [age: $66.46 \pm 9.29 v s .61 .35 \pm 13.90,{ }^{* \star *} P=0.000$; dental caries: $1(0-8)$ vs. $\left.0(0-5),{ }^{* \star *} P=0.000\right]$. The BI and MMSE score were obviously lower and the NIHSS score was higher in the 
abnormal than in the normal BOAS group [BI: 90 (0-100) vs. $100(15-100),{ }^{* \star} P=0.000$; MMSE: $25(2-30) v s .26(4-30),{ }^{*} P$ $=0.013$; NIHSS: $3(0-21)$ vs. $\left.2(1-15),{ }^{* \star} P=0.000\right]$. Interestingly, the incidence of SAP in the abnormal BOAS group was significantly higher than that in the normal BOAS group $\left[\mathrm{n}=56(28.56 \%) v s . \mathrm{n}=14(10.37 \%),{ }^{* \star} P=0.000\right]$. Although the proportion of patients who could independently perform mouth cleaning, the use of a toothbrush and the number of cleaning sites in the abnormal BOAS group tended to be lower than those in the normal group, the differences were not significant (Table 1).

\section{Comparison Of Various Factors Between Sap And Non-sap Groups}

The scores of the BOAS and NIHSS in the SAP group were significantly higher than those in the non-SAP group [BOAS: 7 (5, 12) vs. $6(5,9),{ }^{* \star} P=0.000$; NIHSS: $6(1,21)$ vs. $\left.3(1,15),{ }^{\star \star \star} P=0.000\right]$, while the $\mathrm{BI}$ in the SAP group were significantly lower than that in the non-SAP group [BI: $\left.62.5(0,100) v s .87 .5(20,100),{ }^{\star \star *} P=0.000\right]$. The WST score of the SAP group was worse than that in the non-SAP group $\left[\mathrm{n}=24(34.29 \%) v s . \mathrm{n}=5(7.14 \%),{ }^{* \star} P=0.000\right]$. Moreover, the proportion of indwelling gastric tubes in the SAP group was obviously higher than that in the non-SAP group $\left[\mathrm{n}=14(20.00 \%) v s . n=2(2.86 \%),{ }^{* \star} P=\right.$ 0.001 ; Table 1). There was no significant difference in other variables.

\section{Multivariate logistic regression analysis in ischemic stroke and SAP patients}

Variables with a univariable analysis $P$ value $<0.2$ shown in Table 1, were included in the first risk factor analysis. With the BOAS score included as the dependent variable, multivariable logistic regression analysis was carried out. Finally, a total of 12 independent variables were included in the analysis. The results showed that SAP $(\mathrm{OR}=2.219, P=0.026)$ was the primary related factor for oral hygiene in hospitalized patients with ischemic stroke, followed by the number of dental caries $(\mathrm{OR}=1.292, P=0.005)$ and age $(\mathrm{OR}=1.030, P=0.006)$, while $\mathrm{BI}(\mathrm{OR}=0.986, P=0.019)$ was a protective factor.

Variables with a univariable analysis $P$ value $<0.2$ shown in Table 1 were included in the second risk factor analysis. With SAP as the dependent variable, multivariable logistic regression analysis was carried out. Finally, a total of 8 independent variables were included in the analysis. The results showed that the BOAS score $(\mathrm{OR}=1.678, * \star P=0.001)$ was the primary risk factor for SAP in hospitalized patients with ischemic stroke, while BI $(\mathrm{OR}=0.977, \star \star P=0.002)$ was a protective factor (Table 2).

Table 2

Multivariate logistic regression analysis with oral cleanliness (Model 1) and SAP (Model 2) as the dependent variable

\begin{tabular}{|lllll|}
\hline Risk factors & $\boldsymbol{B}$ & S.E. & $\boldsymbol{P}$ & OR(95\% Cl) \\
\hline Model 1 & & & & \\
\hline SAP & 0.797 & 0.358 & 0.026 & $2.219(1.099,4.480)$ \\
\hline Num. of dental caries & 0.256 & 0.092 & 0.005 & $1.292(1.079,1.546)$ \\
\hline Age & 0.030 & 0.011 & 0.006 & $1.030(1.008,1.052)$ \\
\hline BI & -0.014 & 0.006 & 0.019 & $0.986(0.975,0.998)$ \\
\hline Model 2 & & & & \\
\hline BOAS score & 0.518 & 0.150 & 0.001 & $1.678(1.251,2.252)$ \\
\hline BI & -0.024 & 0.008 & 0.002 & $0.977(0.962,0.991)$ \\
\hline
\end{tabular}

ROC curves for risk factors in the prediction of oral hygiene and SAP in ischemic stroke patients 
ROC curves were constructed to explore whether SAP, the number of dental caries, age and BI could predict oral hygiene in hospitalized patients with ischemic stroke. The area under the ROC curve (AUC) for the combination of SAP, number of dental caries, age and BI was 0.702 , with a standard error of $0.029\left[{ }^{\star \star \star} P=0.000,95 \% \mathrm{Cl}(0.646,0.759)\right]$; the cut-off was 0.305 , with a specificity of $51.9 \%$, sensitivity of $77.6 \%$ and accuracy of $67.1 \%$ (Fig. 2A). The Hosmer-Lemeshow test showed that $\chi^{2}$ was 13.816 , with $\mathrm{df}=8$ and $P=0.087$. ROC curves were also constructed to explore whether the BOAS score and $\mathrm{BI}$ could predict SAP in hospitalized patients with ischemic stroke. The AUC of the combination of BOAS and BI was 0.753 , with a standard error of $0.041\left[{ }^{\star * \star} P=0.000,95 \% \mathrm{Cl}(0.673,0.833)\right]$; the cut-off was 0.443 , with a specificity of $74.3 \%$, sensitivity of $67.1 \%$ and accuracy of $70.7 \%$ (Fig. 2B). The Hosmer-Lemeshow test showed that $\chi^{2}$ was 7.689, with $\mathrm{df}=7$ and $P=0.361$.

\section{Discussion}

Our study revealed the following two new findings. After adjusting for confounders, multivariable logistic regression analysis showed that: 1) SAP was a strongly predictor for abnormal oral hygiene in hospitalized ischemic stroke patients, followed by the number of dental caries, age and $\mathrm{Bl}$; 2) Oral hygiene cleanliness was an independent risk factor for predicting SAP, while the BI was a protective factor in hospitalized SAP patients. To our knowledge, this is the first investigation and predictive model of oral hygiene and SAP in acute ischemic stroke patients, which may be helpful for guiding clinical nursing work.

Previous studies have found that HAP is closely related to oral health [22, 23]. Any inflammation or damage to the oral mucosa could promote bacterial adhesion, colonization, reproduction and infection [24,25]. Migration of this infection through the upper respiratory tract to the lower respiratory tract is common in clinical practice [6]. Therefore, maintaining the integrity of the oral mucosa through daily care is very important to prevent secondary nosocomial infections [25]. However, oral care is not limited to the oral mucosa; the gums, teeth, lips and tongue, and even salivation are included in daily clinical nursing work. The BOAS is a scale containing the five above mentioned items, which should be addressed in oral care [20]. The scale is not only used for the evaluation of nursing care but also to guide nursing intervention for critically ill patients $[20,21,26]$.

Among critically ill patients, stroke patients are susceptible to HAP not only in patients at the early stage but also in the recovery period; furthermore, the incidence of this acquired pneumonia among stroke patients is significantly higher than that of the general patient population $[6,27]$. In the past 10 years, SAP has been widely recognized by clinical researchers $[2-4,7,9]$. The causes of this complication may be related to the stroke-induced immunosuppression, weakening of the pharyngeal reflex, the loss of proprioception or superficial sensation of the oral mucosa, and a weakening of the ability of the lips and tongue to push food into the pharynx after brain injury $[7,8,10,11,17]$. Therefore, screening the risk factors for and establishing a prediction model of oral hygiene in stroke patients is helpful to prevent SAP, HAP or other types of pneumonia in clinical work [7].

There were no significant differences in gender, disease duration, educational background, gastrointestinal diseases, or risk factors of vascular diseases, especially in some subjective evaluation indicators of oral hygiene between the two groups in cohort 1. However, in terms of objective indicators, age, SAP, the number of dental caries, the use of indwelling gastric tubes, and the WST, NIHSS and MMSE score were anatomically or functionally closely related to abnormal oral cleanliness in ischemic stroke patients. These results indicated that 1) the risk of oral hygiene abnormalities increases with age, suggesting that we need to pay more attention to the oral cleanliness of elderly patients with acute ischemic stroke; 2) objective abnormalities of the internal anatomy or pathological structure of the oropharynx and / or respiratory tract may be an important factor of abnormal oral hygiene in ischemic stroke patients, suggesting that we should seriously consider the prevention of dental caries and the management of chest infection and / or indwelling gastric tubes; and 3) cognitive function strengthening and ADLs rehabilitation may help improve oral cleanliness in patients with acute ischemic stroke. 
Moreover, we analyzed 70 SAP patients in this study independently and compared them with non-SAP patients matched by age and gender. The results showed that there were significant differences in the WST score, indwelling gastric tube, NIHSS score, and BI between SAP and non-SAP patients. Particularly, these indicators were significantly more severe in the SAP group than in the non-SAP group. Interestingly, the SAP group had significantly higher BOAS scores than the non-SAP group. Therefore, is poor oral hygiene an independent risk factor for SAP? This point has not been raised in the previous literature, and we conducted the following analysis.

Our study found that there is a strong correlation between SAP and BOAS score abnormalities. In general, abnormal oral hygiene was most closely related to personal hygiene habits. However, this situation may change in the presence of certain diseases, such as nutritional or exercise-induced immune suppression, long-term use of antibiotics, dehydration, etc [2830]. Little has been reported regarding whether lung infections affect oral hygiene [29]. This study found that SAP may be the leading risk factor for abnormal oral hygiene in patients with acute ischemic stroke, although the exact reason is not clear. Surprisingly, the BOAS score was an independent risk factor for SAP, suggesting that abnormal oral hygiene has a higher risk coefficient than swallowing disorders, which is different from previous studies [8,9]. Combined with two multiple regression analyses, we determined that oral hygiene abnormalities and SAP interact with each other and that this interaction may form a vicious cycle (Fig. 3). This is an important discovery that has not been reported before.

Dental caries have been recognized as one of the three major human diseases, along with parallel with cancer and cardiovascular diseases [31, 32]. Its etiology is complex and may be related to bacteria, the oral microenvironment and the time of action [33]. Carbohydrates are the main source of food for Chinese people. A small amount of starch is easily deposited on the tooth surface after the meal and then forms a mixture with the trace protein in the saliva. With a suitable temperature and sufficient time, bacteria and even parasites and viruses can easily reproduce, and visible plaque and unpleasant oral odors are quickly generated [32,34]. From the perspective of pathophysiology, caries is the result of longterm adhesion of plaque to teeth and destruction of organic matter [33,34]. Patients with dental caries are more likely to have food residues in the cavities after meals, which makes it difficult to completely remove plaque. Therefore, caries is likely the cause of poor oral health. Comparatively, this situation is even worse in stroke patients [35]. From the results above, dental caries plays an important negative role $(\mathrm{OR}=1.292)$ in the abnormal oral cleanliness of acute ischemic stroke patients (Fig. 3).

Compared with the above risk variables, BI was the only protective factor in the two regression analyses (Fig. 3). It plays an important role in oral hygiene and SAP in patients with ischemic stroke, suggesting that we need to pay more attention to the rehabilitation of the ADLs of early diagnosed patients, which will help improve oral hygiene and SAP prevention.

ROC curve analysis suggested that the combination of SAP, dental caries, age and BI has enough discriminative power to distinguish oral hygiene in acute ischemic stroke patients; this power also exists in the efficiency of the combined BOAS score and BI in predicting SAP. The sensitivity and specificity of both models were satisfactory, with accuracy of $67.1 \%$ and 70.7\%, respectively, in clinical practice.

Some limitations of this study should be noted: 1) a relatively small sample size of SAP patients was included in the present study; 2) to reduce the SAP diagnosis bias, case collection time should have been extended to the 7th day of the disease course; 3 ) patients with severe aphasia or tracheotomy were not included; and 4) biochemical indicators, such as inflammatory factors, were not included as potential risk factors. Therefore, an increase in the sample size and observational markers included can help to further analyze the mutual roles of oral hygiene and SAP in patients with acute stroke.

\section{Conclusions}

Abnormal oral cleanliness and SAP have mutually primary risk roles in patients with acute ischemic stroke. Dental caries and aging are important risk factors for oral health disorders. Improving the ADLs would have protective effects on both 
oral hygiene and SAP prevention in stroke patients. Interventions for these risk factors may improve oral cleanliness and reducing the occurrence of SAP in acute ischemic stroke patients.

\section{Declarations}

\section{Acknowledgements}

None

\section{Author Contributions}

Conceived and designed the study: X.Y., H.C., X.T., and Q.W. Performed the study: X.Y., B.D., Y.H., J.W., C.L., H.X., M.L., A.C., Z.H., J.H., J.Z., T.H., X.T., and Q.W. Revised the paper for intellectual content: W.Y., Q.Y., X.G., X.T., and Q.W. Wrote the paper: X.Y., X.T., and Q.W. All authors read and approved the final manuscript.

\section{Funding}

This work was supported by the Natural Science Foundations of Guangdong of China (NO: 2017A030311010), Initiated Foundation of Zhujiang Hospital (No: 02020318005), Leading Talent in Talents Project Guangdong High-level Personnel of Special Support Program, and Scientific Research Foundation of Guangzhou (NO: 201704030080) to Q.W., China Postdoctoral Science Foundation funded project (NO. 2019M662987) to W.Y., and Natural Science Foundation of Hunan Province (2018JJ6104), Science and Technology Planning Project of Changsha (ZD1702033) and Renshu Fundation of Hunan Provincial People's Hospital (RS201812) to X.T.

\section{Availability of data and materials}

The datasets used and/or analyzed during the current study are available from the corresponding author on reasonable request.

\section{Ethics approval and consent to participate}

This cross-sectional study was approved by the Ethics Committee of Zhujiang Hospital of Southern Medical University and Hunan Provincial People's Hospital of Hunan Normal University (Human Ethics Number: 2020-KY-015-01) and conducted according to the principles outlined in the revised Declaration of Helsinki of 1975 and the National Institutes of Health Human Subjects Policies and Guidelines released in 1999.

\section{Consent for publication}

All of the listed authors approved the final version for submission and publication.

\section{Competing interests}

The authors declare that they have no conflict of interest.

\section{References}

1. Hu R, Zhang C, Xia J, Ge H, Zhong J, Fang X, Zou Y, Lan C, Li L, Feng H: Long-term Outcomes and Risk Factors Related to Hydrocephalus After Intracerebral Hemorrhage. Translational stroke research 2020.

2. Zapata-Arriaza E, Mancha F, Bustamante A, Moniche F, Pardo-Galiana B, Serrano-Gotarredona P, Navarro-Herrero S, Pallisa E, Faura J, Vega-Salvatierra A et al: Biomarkers predictive value for early diagnosis of Stroke-Associated Pneumonia. Annals of clinical and translational neurology 2019, 6(9):1882-1887. 
3. Palli C, Fandler S, Doppelhofer K, Niederkorn K, Enzinger C, Vetta C, Trampusch E, Schmidt R, Fazekas F, Gattringer T: Early Dysphagia Screening by Trained Nurses Reduces Pneumonia Rate in Stroke Patients: A Clinical Intervention Study. Stroke 2017, 48(9):2583-2585.

4. Nam KW, Kim TJ, Lee JS, Kwon HM, Lee YS, Ko SB, Yoon BW: High Neutrophil-to-Lymphocyte Ratio Predicts StrokeAssociated Pneumonia. Stroke 2018, 49(8):1886-1892.

5. Kishore AK, Jeans AR, Garau J, Bustamante A, Kalra L, Langhorne P, Chamorro A, Urra X, Katan M, Napoli MD et al: Antibiotic treatment for pneumonia complicating stroke: Recommendations from the pneumonia in stroke consensus (PISCES) group. European stroke journal 2019, 4(4):318-328.

6. Schwarz M, Coccetti A, Murdoch A, Cardell E: The impact of aspiration pneumonia and nasogastric feeding on clinical outcomes in stroke patients: A retrospective cohort study. Journal of clinical nursing 2018, 27(1-2):e235-e241.

7. Wagner C, Marchina S, Deveau JA, Frayne C, Sulmonte K, Kumar S: Risk of Stroke-Associated Pneumonia and Oral Hygiene. Cerebrovascular diseases 2016, 41(1-2):35-39.

8. Hoffmann S, Harms H, Ulm L, Nabavi DG, Mackert BM, Schmehl I, Jungehulsing GJ, Montaner J, Bustamante A, Hermans $\mathrm{M}$ et al: Stroke-induced immunodepression and dysphagia independently predict stroke-associated pneumonia - The PREDICT study. Journal of cerebral blood flow and metabolism : official journal of the International Society of Cerebral Blood Flow and Metabolism 2017, 37(12):3671-3682.

9. Eltringham SA, Kilner K, Gee M, Sage K, Bray BD, Smith CJ, Pownall S: Factors Associated with Risk of StrokeAssociated Pneumonia in Patients with Dysphagia: A Systematic Review. Dysphagia 2019.

10. Brämer D, Günther A, Rupprecht S, Nowack S, Adam J, Meyer F, Schwab M, Surber R, Witte OW, Hoyer H et al: Very Low Frequency Heart Rate Variability Predicts the Development of Post-Stroke Infections. Translational stroke research 2019, 10(6):607-619.

11. Teuschl Y, Trapl M, Ratajczak P, Matz K, Dachenhausen A, Brainin M: Systematic dysphagia screening and dietary modifications to reduce stroke-associated pneumonia rates in a stroke-unit. PloS one 2018, 13(2):e0192142.

12. Hua F, Xie H, Worthington HV, Furness S, Zhang Q, Li C: Oral hygiene care for critically ill patients to prevent ventilatorassociated pneumonia. The Cochrane database of systematic reviews 2016, 10:CD008367.

13. de Lacerda Vidal CF, Vidal AK, Monteiro JG, Jr., Cavalcanti A, Henriques APC, Oliveira M, Godoy M, Coutinho M, Sobral $\mathrm{PD}$, Vilela CA et al: Impact of oral hygiene involving toothbrushing versus chlorhexidine in the prevention of ventilatorassociated pneumonia: a randomized study. BMC infectious diseases 2017, 17(1):112.

14. Haghighi A, Shafipour V, Bagheri-Nesami M, Gholipour Baradari A, Yazdani Charati J: The impact of oral care on oral health status and prevention of ventilator-associated pneumonia in critically ill patients. Australian critical care: official journal of the Confederation of Australian Critical Care Nurses 2017, 30(2):69-73.

15. Robba C, Bonatti G, Battaglini D, Rocco PRM, Pelosi P: Mechanical ventilation in patients with acute ischaemic stroke: from pathophysiology to clinical practice. Critical care (London, England) 2019, 23(1):388.

16. Wise MP, Williams DW: Oral care and pulmonary infection - the importance of plaque scoring. Critical care (London, England) 2013, 17(1):101.

17. Smith CJ, Kishore AK, Vail A, Chamorro A, Garau J, Hopkins SJ, Di Napoli M, Kalra L, Langhorne P, Montaner J et al: Diagnosis of Stroke-Associated Pneumonia: Recommendations From the Pneumonia in Stroke Consensus Group. Stroke 2015, 46(8):2335-2340.

18. Zapata-Arriaza E, Serrano-Gotarredona P, Navarro-Herrero S, Moniche F, Pardo-Galiana B, Pallisa E, Vega-Salvatierra Á, Mancha F, Escudero-Martínez I, Bustamante A et al: Chest Computed Tomography Findings and Validation of Clinical Criteria of Stroke Associated Pneumonia. Journal of stroke 2019, 21(2):217-219.

19. Osawa A, Maeshima S, Tanahashi N: Water-swallowing test: screening for aspiration in stroke patients. Cerebrovascular diseases 2013, 35(3):276-281. 
20. Kaya H, Turan Y, Tunali Y, Aydin GO, Yuce N, Gurbuz S, Tosun K: Effects of oral care with glutamine in preventing ventilator-associated pneumonia in neurosurgical intensive care unit patients. Applied nursing research : ANR 2017, 33:10-14.

21. Zand F, Zahed L, Mansouri P, Dehghanrad F, Bahrani M, Ghorbani M: The effects of oral rinse with $0.2 \%$ and $2 \%$ chlorhexidine on oropharyngeal colonization and ventilator associated pneumonia in adults' intensive care units. Journal of critical care 2017, 40:318-322.

22. Warren C, Medei MK, Wood B, Schutte D: A Nurse-Driven Oral Care Protocol to Reduce Hospital-Acquired Pneumonia. The American journal of nursing 2019, 119(2):44-51.

23. Zuercher P, Moret CS, Dziewas R, Schefold JC: Dysphagia in the intensive care unit: epidemiology, mechanisms, and clinical management. Critical care (London, England) 2019, 23(1):103.

24. Bandara H, Samaranayake LP: Viral, bacterial, and fungal infections of the oral mucosa: Types, incidence, predisposing factors, diagnostic algorithms, and management. Periodontology 2000 2019, 80(1):148-176.

25. Bellissimo-Rodrigues WT, Menegueti MG, de Macedo LD, Basile-Filho A, Martinez R, Bellissimo-Rodrigues F: Oral mucositis as a pathway for fatal outcome among critically ill patients exposed to chlorhexidine: post hoc analysis of a randomized clinical trial. Critical care (London, England) 2019, 23(1):382.

26. Ames NJ, Sulima P, Yates JM, McCullagh L, Gollins SL, Soeken K, Wallen GR: Effects of systematic oral care in critically ill patients: a multicenter study. American journal of critical care : an official publication, American Association of Critical-Care Nurses 2011, 20(5):e103-114.

27. Yu KJ, Moon H, Park D: Different clinical predictors of aspiration pneumonia in dysphagic stroke patients related to stroke lesion: A STROBE-complaint retrospective study. Medicine 2018, 97(52):e13968.

28. Needleman I, Ashley P, Fine P, Haddad F, Loosemore M, de Medici A, Donos N, Newton T, van Someren K, Moazzez R et al: Oral health and elite sport performance. British journal of sports medicine 2015, 49(1):3-6.

29. Chebib N, Muller F, Prendki V: [Pneumonia of the elderly and its link to oral health]. Revue medicale suisse 2018, 14(626):2007-2011.

30. Humphreys K, Vadher D, Allen Y, Patel N, Shah S: Examining the links between hydration, nutrition and mouth health. British journal of nursing (Mark Allen Publishing) 2017, 26(10):566-570.

31. Iranzo-Cortes JE, Montiel-Company JM, Almerich-Silla JM: Caries diagnosis: agreement between WHO and ICDAS II criteria in epidemiological surveys. Community dental health 2013, 30(2):108-111.

32. Moynihan PJ, Kelly SA: Effect on caries of restricting sugars intake: systematic review to inform WHO guidelines. Journal of dental research 2014, 93(1):8-18.

33. Kutsch VK, Young DA: New directions in the etiology of dental caries disease. Journal of the California Dental Association 2011, 39(10):716-721.

34. Guo Y, Tian LL, Zhang FY, Bu YH, Feng YZ, Zhou HD: Dental caries and risk indicators for patients with leprosy in China. International dental journal 2017, 67(1):59-64.

35. Kim HT, Park JB, Lee WC, Kim YJ, Lee Y: Differences in the oral health status and oral hygiene practices according to the extent of post-stroke sequelae. Journal of oral rehabilitation 2018, 45(6):476-484.

\section{Figures}




\begin{tabular}{|c|c|}
\hline & $\begin{array}{l}\text { Excluded: } 544 \\
\text { (1) Severe aphasia: } 141 \\
\text { (2) Tracheotomy: } 38 \\
\text { (3) Severe liver dysfunction: } 47 \\
\text { (4) Severe kidney dysfunction : } 33 \\
\text { (5) Non-cooperation evaluation: } 186 \\
\text { (6) Refuse to participate: } 99\end{array}$ \\
\hline $\begin{array}{l}331 \text { patients included in our study } \\
\text { (1) Normal BOAS group }(\mathrm{n}=135) \\
\text { (2) Abnomal BOAS group }(\mathrm{n}=196) \\
\text { Mild dysfunction: } 193 \\
\text { Moderate dysfunction: } 3 \\
\text { Severe dysfunction: } 0\end{array}$ & $\rightarrow \quad \begin{array}{l}140 \text { ischemic stroke patients } \\
\text { (1) SAP group }(\mathrm{n}=70) \\
\text { Normal BOAS score: } 14 \\
\text { Abnormal BOAS score: } 56 \\
\text { (2) non- SAP group }(\mathrm{n}=70)\end{array}$ \\
\hline
\end{tabular}

\section{Figure 1}

Flow diagram of study selection process BOAS, Beck oral assessment scale; SAP, Stroke-associated pneumonia
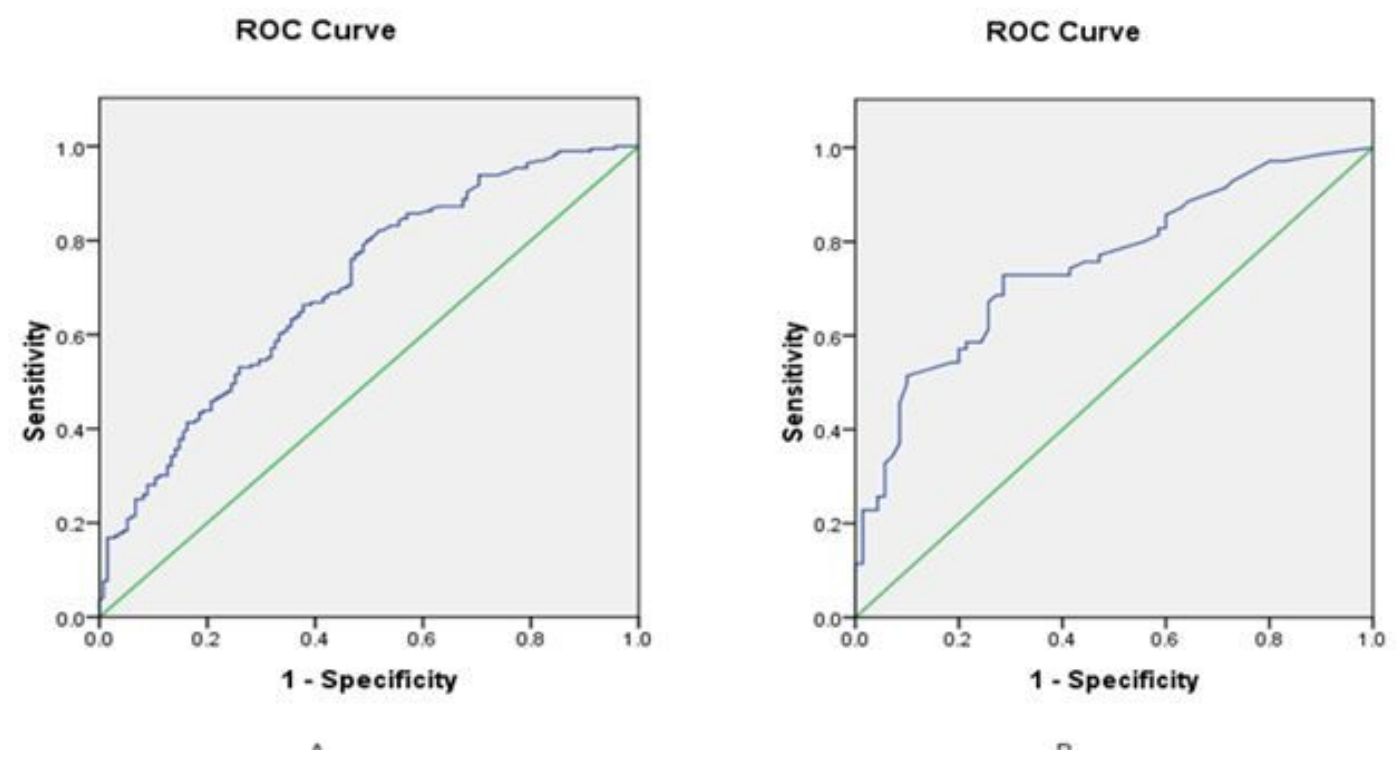

Figure 2

ROC curve for predicting oral hygiene (A) and SAP (B) in patients with acute ischemic stroke $\triangle \mathrm{ROC}$, receiver operating characteristic; SAP, Stroke-associated pneumonia. 


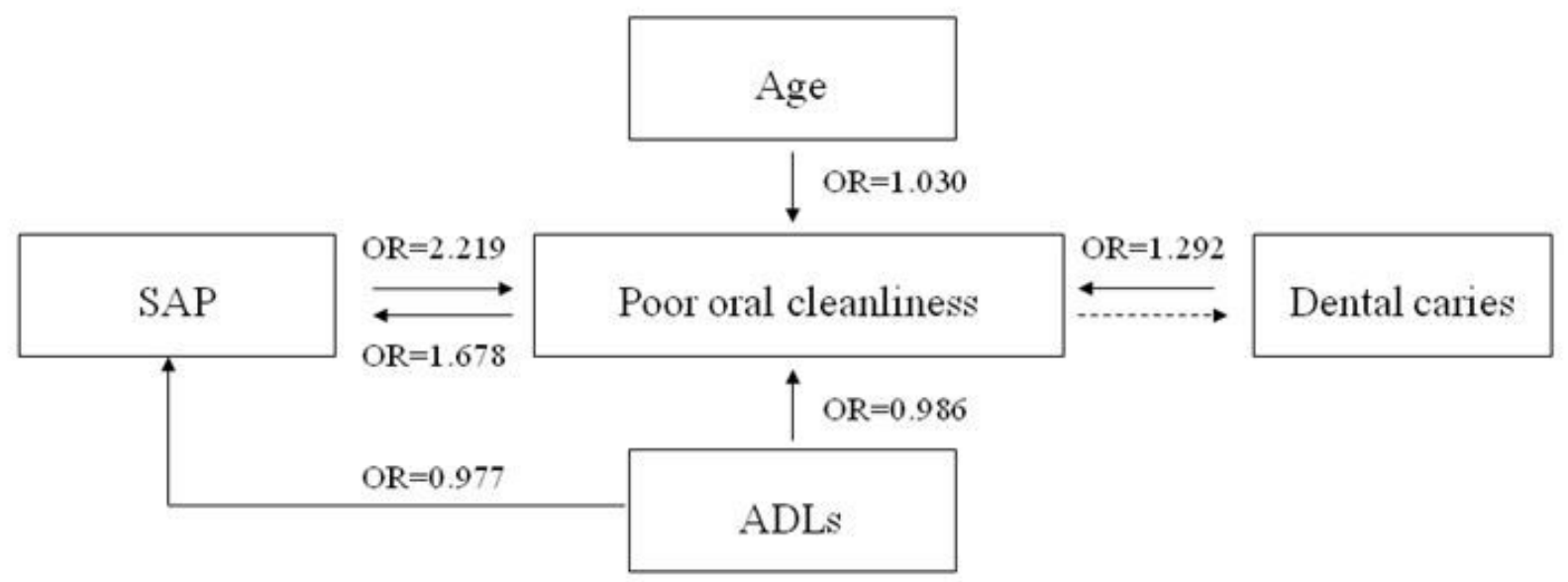

Figure 3

Risk schematic of this study $₫ A D L s$, activities of daily living; SAP, Stroke-associated pneumonia; OR, Odds ratio 